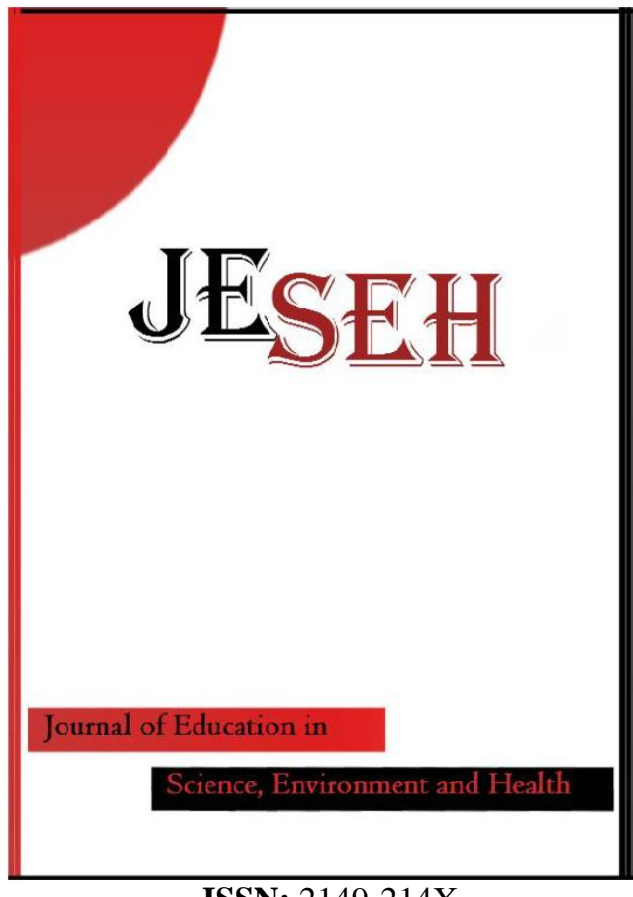

Journal of Education in Science, Environment and Health

$\underline{\text { www.jeseh.net }}$

Enhancing the Critical Thinking Skills of Grade 8 Chemistry Students Using an Inquiry and Reflection Teaching Method

Nathalie Farah, Zalpha Ayoubi

Lebanese University

ISSN: $2149-214 \mathrm{X}$

To cite this article:

Farah, N. \& Ayoubi, Z. (2020). Enhancing the critical thinking skills of grade 8 chemistry students using an inquiry and reflection teaching method. Journal of Education in Science, Environment and Health (JESEH), 6(3), 207-219. DOI:10.21891/jeseh.656872

This article may be used for research, teaching, and private study purposes.

Any substantial or systematic reproduction, redistribution, reselling, loan, sub-licensing, systematic supply, or distribution in any form to anyone is expressly forbidden.

Authors alone are responsible for the contents of their articles. The journal owns the copyright of the articles.

The publisher shall not be liable for any loss, actions, claims, proceedings, demand, or costs or damages whatsoever or howsoever caused arising directly or indirectly in connection with or arising out of the use of the research material. 


\title{
Enhancing the critical thinking skills of grade 8 chemistry students using an inquiry and reflection teaching method
}

\author{
Nathalie Farah, Zalpha Ayoubi
}

\begin{tabular}{|c|c|}
\hline Article Info & Abstract \\
\hline Article History & In contrast to traditional science instruction, which encourages students to \\
\hline Recei & adoption of scientific process skills by students, as well as the teaching of critical \\
\hline 29 March 2019 & thinking skills. Lebanese Chemistry teachers detected lack in middle school and \\
\hline Accepted: & $\begin{array}{l}\text { high school students' critical thinking skills, such as analyzing data, interpreting } \\
\text { experiments' results and arguing. Consequently, we elaborated the Inquiry and }\end{array}$ \\
\hline 01 February 2020 & Reflection teaching method (I\&R) based on White and Fredericsen's method \\
\hline Keywords & $\begin{array}{l}\text { (1998) and implemented it for three months to grade } 8 \text { chemistry students, in one } \\
\text { Lebanese private school. Then we compared the control and experimental group }\end{array}$ \\
\hline Critical thinking & students' scores on the Critical Thinking Test and the final exam. Findings \\
\hline Inquiry & ed that the experimental group students improved their critical thinking \\
\hline Metacognition & skills significantly, while the control group students' critical thinking remained \\
\hline Reflection & the same. \\
\hline
\end{tabular}

\section{Introduction}

There has been growing interest across the world in ways of developing children's thinking and learning skills (Fisher, 2005), as well as developing educational programs that assume that all individuals, not just elite, can become competent thinkers (Zohar, 2001). This interest was not only exclusive for schools and high-schools' students (Changwong, 2018); in fact, promoting students' critical thinking has been also an essential goal of higher education in many universities' faculties (Barroga, 2019; Zulfaneti, 2018). In contrast to traditional science instruction, which emphasizes lectures to efficiently present scientific information and encourages students to memorize facts from textbooks, today's science instruction emphasizes on problem-solving and inquiry-based laboratory activities. In other words, it emphasizes implementing critical thinking approach to the process of education and instruction (Burke, 2008; Fennimore, 1990; Kaplan, 2017; Karakoç, 2016; Padilla, 1990; Uribe Enciso et al., 2017; Zohar, 2005).

The particular ways in which people apply their minds to solving problems are called thinking skills. This term refers to the human capacity to think in conscious ways to achieve certain purposes. According to Fisher (2006), such processes include remembering, questioning, forming concepts, planning, reasoning, imagining, solving problems, making decisions and judgments, and translating thoughts into words. Perry (2016) linked between inquiry and critical thinking: "through a combination of hands-on and minds-on learning, inquiry engages students in a process through which they learn science content best". Other researchers saw inquiry as being the essence of critical thinking such as Kitot (2010), Caswell (2017) and Duran (2016) who stressed the effectiveness of inquiry teaching in enhancing students' critical thinking. Research has confirmed the value of an inquiry approach in fostering student learning (Bransford et al., 2000; Smallhorn, 2015), and suggested that inquiry-based learning contributes to improving students' abilities in system thinking (Orit Ben Zevi, 2005), as well as developing students' abilities in engagement, motivation, and self-confidence (Center for Inspired Teaching, 2017).

On the other hand, according to Magno (2010), metacognition has a significant path to critical thinking. Metacognition, which is the cognition about own cognition (Schneider, 2001), refers to higher order thinking that involves active control over the thinking processes involved in learning. Activities such as planning how to approach a given learning task, monitoring comprehension, and evaluating progress toward the completion of a task are metacognitive in nature" (Kizlik, 2011). Several studies have showed the positive effects of metacognitive guidance on learning outcomes (Zion, Michalsky \& Mavarech, 2005).

This leads to a conclusion that the conjunction between inquiry and metacognition as a teaching method might develop critical thinkers. White and Fredericksen (1998) developed a computer enhanced, middle school science 
curriculum that develops students' metacognitive knowledge and skills through a process of scaffolded inquiry. This method of teaching includes three phases: scaffolded inquiry, reflective assessment and generalized inquiry and reflection. Findings revealed that this approach was beneficial for both low-achieving and high-achieving students who understood the nature of inquiry, acquired the habits of thought, and considered the difficult subject of Physics understandable and interesting (White \& Fredericsen, 1998). Moreover, White \& Shimoda (1999), introduced a software, the SCI-WISE, to engage in "inquiry about inquiry," thereby making inquiry and metacognition topics of investigation. However, there is a need to create innovative instructional methods which do not depend on software or computer skills, especially in Lebanon where many schools are not well equipped with technology. Consequently, we elaborated and implemented the Inquiry and Reflection method (similar to White and Fredericsen's method without being a computer enhanced method), which includes four phases: the scaffolded inquiry, the reflective assessment, the argumentation and the generalization.

In the first phase of the Inquiry and Reflection method (I\&R), students make conjectures, plan and conduct experiments, collect and analyze data, interpret results and draw conclusions. In the second and third phases, students compare and evaluate their own and each other's work, students also recognize what they have to argue about then they write out their case in support of the claims or positions they seek to defend. Finally, they resolve their dispute by agreeing that one conclusion is better supported than the others (O'Rourke, 2005).

This instructional method aims for students to perform analysis, interpretation, and argumentation skills. Analysis skill refers to the ability to visualize, articulate, conceptualize or solve problems by making decisions that are sensible given the available information. The ability to think analytically and creatively is crucial for success in the modern workforce, particularly for graduate students who aim to become physicians or researchers (Abdullah, 2015). Interpretation is a communication process designed to discover, to reveal meanings, to gain a deeper understanding of concepts by tying those concepts to experiments, since it requires a level of inference beyond what can be literally seen (Zagallo, 2016); it encompasses such sub-skills as: identification, categorization and expression (Wang, 2017). While argumentation, called the language of science (Duschl, 1999), has also been identified as a possible mechanism for conceptual growth and change (Nussbaum, 2003).

\section{The Inquiry and Reflection Teaching Method}

The Inquiry and Reflection Teaching Method includes four phases:

Scaffolded inquiry: Students are involved in "open-ended" questions and experience hypothesizing, investigating, planning experiment, conducting experiment, observing, analyzing the findings and concluding.

Reflective assessment: Students evaluate their own and each other's research. This process enables them to reason carefully, so the habits of thought will be involved in their skills.

Argumentation: students gather evidences to support the claims they seek to defend and then resolve their dispute by agreeing that one conclusion is better supported than another.

Generalized Inquiry and Reflection: the inquiry cycle, in conjunction with reflection, is repeated to help students refine their inquiry and reflection processes so they can apply to new learning situations and real-world situations.

\section{Purpose of the study}

The aim of this study is to investigate the effect of the Inquiry and Reflection (I\&R) instructional method on students' critical thinking skills. Although critical thinking encompasses many skills, this study emphasizes on only three of them, namely the analysis, the interpretation and the argumentation skills. These skills are considered important for students in schools and their everyday life.

\section{Research Questions}

This research tries to answer the question: Does the I\&R method of teaching enhance grade 8 students' critical thinking. Particularly, we sought answers to the following research questions: 
$\mathrm{Q}_{1}$ : Does the I\&R method of teaching affect grade 8 students' analysis skills?

$\mathrm{Q}_{2}$ : Does the I\&R method of teaching affect grade 8 students' interpretation skills?

$\mathrm{Q}_{3}$ : Does the I\&R method of teaching affect grade 8 students' argumentation skills?

\section{Research Hypotheses}

The research hypotheses corresponding to the above research questions are:

$\mathrm{H}_{1}$ : Students in the experimental group will significantly have better analysis skills than the control group students.

$\mathrm{H}_{2}$ : Students in the experimental group will significantly have better interpretation skills than the control group students.

$\mathrm{H}_{3}$ : Students in the experimental group will significantly have better argumentation skills than the control group students.

\section{Method}

A mixed research was conducted in order to answer the research question. The quantitative part consisted of a quasi-experimental design using a Critical Thinking test as a pre-test and a post-test. In addition, questions in the final exam, which included an "Analysis" question, an "Interpretation" question and an "Argumentation" problem were analyzed qualitatively and quantitatively.

\section{Participants}

The participants in this study were 38 grade 8 students from one Lebanese private school. They were distributed to two sections of 19 students each. An exam covering the content taught during the first semester which includes solutions, atoms, and compounds took place before the I\&R implementation, where both groups were taught via the traditional method. By comparing both groups' grades on this exam, we didn't find significant differences between the two sections in terms of achievement, in other words, students in both sections had similar academic backgrounds. At the beginning of the second semester, section A was chosen, randomly, as the control group and section B as the experimental group. Both groups were similar in terms of students' age, gender and socio-economic background as they live in the same geographical area and belong to the same economic status.

\section{Procedure}

In the two semesters, the first researcher, who was the Chemistry teacher in both sections, taught both groups the same Chemistry content. In the first semester, both groups learned via the traditional method while in the second semester the experimental group students learned via the I\&R teaching method and the control group students continued learning via the traditional method. The I\&R method was implemented for eight weeks, 3 hours per week, covering the four chapters normally taught during the second semester: the "Chemical Reactions", the "Types of Chemical Reactions", the "Rates of Chemical Reactions" and the "Acidic and Basic Solutions". The steps of the I\&R method were repeated in each of the four lab sessions; however, some of the scaffolding was removed each time. In the first session "Chemical Reactions", the experiments were designed by the teacher who prepared all the materials; in the second session "Types of Chemical Reactions" the students gathered and prepared all the necessary materials for performing the experiments designed by their teacher; however, in the third session "Rates of Chemical Reactions", students participated in the designing of the experiments, while in the fourth one "Acidic and Basic solutions" they designed all the experiments and gathered all the materials. From one lab session to another, the teacher asked students to make predictions about what they thought might happen in some simple real-world situations, in other words, they were asked to engage in a "thought experiment". The teacher had the class generate a set of alternative hypotheses, investigate, design experiments, analyze data, and present conclusions. Then the class got together to try to reach a consensus about which hypothesis best accounts for their results and which was the most accurate and useful, leading them to "discover laws". For this process, they had to criticize each other's hypotheses and conclusions and attempt to prove them wrong. An example of one of the lab sessions, acidic and basic solutions, appears in Table 1. 
The control group students were taught the same science content by the same teacher mainly using lectures without any explicit attempt to stimulate students to engage in metaconceptual processes. In other words, the teacher provides the scientific explanations in the form of a lecture before the laboratory experiments. They discuss their observations after performing experiments. Throughout these discussions, the teacher didn't encourage students to predict the results of the experiments or to compare their initial ideas or predictions with the observed results.

Table 1: Example of one lab session

Duration: 40min

Title: Acidic and basic solutions

\section{Objectives:}

- Defining the terms: acid, base, $\mathrm{pH}$

- Classifying solutions as acids or bases

- Learning the concept of neutralization

Keywords: acid, base, $\mathrm{pH}$, neutralization

Researches: Students conducted a library research to define the terms: acid, base, $\mathrm{pH}$ and neutralization

\section{Questions:}

- What are the natures of: juice; milk; vinegar; water; soap; shampoo; oil; Pepsi; detergent

- Is it true that any acid added to any base gives a neutral solution?

\section{Hypotheses:}

Each group made his own hypotheses about the nature of the following solutions: juice; milk; vinegar; water; soap; shampoo; detergent; oil; Pepsi; $20 \mathrm{ml} \mathrm{HCl}+20 \mathrm{ml} \mathrm{NaOH} ; 20 \mathrm{ml} \mathrm{HCl}+40 \mathrm{ml} \mathrm{NaOH}$; $40 \mathrm{ml} \mathrm{HCl}+$ $20 \mathrm{ml} \mathrm{NaOH} ; 20 \mathrm{ml}$ vinegar+20ml NaOH .

\section{Experiments:}

Students planned to determine the $\mathrm{pH}$ of the following solutions, using a $\mathrm{pH}$ paper: juice; milk; vinegar; water; soap; shampoo; oil; Pepsi; detergent (solutions from everyday life)

$20 \mathrm{ml} \mathrm{HCl}+20 \mathrm{ml} \mathrm{NaOH}$ (to verify the neutralization)

$20 \mathrm{ml} \mathrm{HCl}+40 \mathrm{ml} \mathrm{NaOH}$

$40 \mathrm{ml} \mathrm{HCl}+20 \mathrm{ml} \mathrm{NaOH}$

$20 \mathrm{ml}$ vinegar $+20 \mathrm{ml} \mathrm{NaOH}$. (They chose another acid in order to compare the $\mathrm{pH}$ in both cases)

\section{Materials:}

Each group had a pH paper, an $\mathrm{HCl}$ solution, a $\mathrm{NaOH}$ solution, a bottle of vinegar, a bottle of milk, a bottle of juice, a bottle of water, a bottle of soap, a bottle of shampoo, a bottle of oil, a bottle of Pepsi, a bottle of detergent, a $50 \mathrm{ml}$ of graduate cylinder and a dropper.

\section{Reports:}

A week later, each student should present a lab report which includes: the hypotheses, the materials used, the procedure followed, the observations, the analysis and the conclusion he or she made.

\section{Debate:}

In the following session, groups should expose the investigations they did during the week about laws they discovered and their limitations, then the class got together to try to reach a consensus about which hypothesis best accounts for their results and was the most accurate and useful. As part of this process, they have to criticize each other's hypotheses and conclusions and attempt to prove them wrong.

\section{Instruments}

Critical thinking skills were measured by a 25 -item test inspired by a sample of James Madison Critical Thinking Test, a worldwide known Critical Thinking test, that was adapted to the Lebanese curricula by six Lebanese teachers and educators, who first chose the items related to the Lebanese Chemistry grade 8 syllabus, and then translated and reformulated the questions for a better understanding. This test was used as pre- and 
post-test to measure and compare both groups' critical thinking skills, before and after the I\&R method implementation. It covered the analysis, the interpretation and the argumentation skills. The analysis skills appear in 7 questions where students have to distinguish necessary and sufficient conditions, to distinguish unstated conclusions, to distinguish reasons, and to discern whether pairs of claims are consistent, contrary, contradictory, or paradoxical. The interpretation skills appear in 7 questions which are mainly about identifying and avoiding errors in reasoning. The argumentation skills appear in 11 questions, where students have to evaluate whether an inductive argument is strong or weak, to evaluate whether a deductive argument is valid or invalid, to distinguish supporting, conflicting, compatible, and equivalent claims arguments, explanations, descriptions and representations, and to recognize ambiguity and unclearness in claims, arguments, and explanations. An item for each dimension is given as example in Table 2. A pilot test was performed where the test was administered to 50 grade 8 students from two schools who did not participate in this study. The validity of the test was provided by the teachers and educators from the two schools and the reliability was verified by the Kuder-Richardson coefficient value KR20 = 0.807. In addition, a final exam, including an "Analysis" question, an "Interpretation" question and an "Argumentation problem" was also used to measure critical thinking skills. This test was administered to both groups' students at the end of the second semester after the implementation of the I\&R method was completed. The test questions were validated by Chemistry Education specialists.

Table 2: Examples of the Critical Thinking test' items

Analysis skills:

Students have to distinguish necessary and sufficient conditions

Interpretation skills:

Identifying and avoiding errors in reasoning

The argumentation skills:

Students have to evaluate whether a deductive argument is valid or invalid
Identify the correct relationship in the question below.

Chilling pure water at sea level to a temperature below zero degrees Celsius is:

A. Only a necessary condition for pure water to freeze.

B. Only a sufficient condition for pure water to freeze.

C. Both a necessary and a sufficient condition for pure water to freeze.

D. Neither a necessary nor a sufficient condition for pure water to freeze.

"Professor Fernandez is a famous medical doctor. So, I believe her when she says that global atomic energy is the cheapest way to produce electricity."

A. Professor Fernandez's claim suggests that one thing caused another, when actually one thing merely happened after the other.

B. Professor Fernandez makes a general claim about a group based on a sample that is not representative of the group.

C. Professor Fernandez is not an expert on atomic energy.

D. There is nothing wrong with the remark.

E. Nuclear energy production creates poisonous radiation that will last for centuries.

(1) If today is Friday, then we have a test. (2) If today is Saturday, then we can sleep late. (3) Either we do not have a test or we cannot sleep late.

A. Today is neither Friday nor Saturday.

B. Today is Friday and we cannot sleep late.

C. Either it is not Friday or it is not Saturday.

D. Today is Saturday, but we have a test.

E. None of the above.

\section{Data Analysis}

SPSS program was used to analyze the obtained data quantitatively. Independent-samples t-test was used to determine whether there was a significant difference between the critical thinking pre-test and post-test and the 
final exam questions mean scores of the students in both experimental and control groups. Moreover, the Chisquare test was used to determine whether or not there was a significant difference between both groups' argumentation skills. The .05 level of significance was accepted for all the analyses performed in this study. In addition, the students' responses to the final exam questions were further analyzed qualitatively.

\section{Results and Discussion}

\section{Results related to the Critical Thinking Test}

Prior to treatment, an independent samples t-test was employed to the Critical Thinking pre-test to determine if there was a statistically significant difference between control and experimental groups. Results of the independent-samples t-test regarding the Critical Thinking pre-test are provided in Table 3 below. According to Table 3, the mean pre-test score of the experimental group was $M=10.052$, the mean pre-test score of the control group was $\mathrm{M}=9,882$, and the difference between the two groups was not significant $(\mathrm{p}>0.05, \mathrm{t}=-.375)$. This result indicated that students' critical thinking skills in both experimental and control groups were similar at the beginning of the experimental study.

Table 3. Independent sample t-test results of the Critical Thinking pre-test

\begin{tabular}{cccccc}
\hline Group & $\mathrm{N}$ & Mean & SD & $\mathrm{t}$ & $\mathrm{p}$ \\
\hline Control & 19 & 9.882 & 2.689 & \multirow{2}{*}{.375} & .710 \\
Experimental & 19 & 10.052 & 1.649 & & \\
\hline
\end{tabular}

Results of the independent-samples t-test regarding the Critical Thinking post-test are provided in Table 4 below. According to Table 4, the mean post-test score of the experimental group was $M=18.368$, the mean post-test score of the control group was $\mathrm{M}=10.588$, and the difference between the two groups was significant $(\mathrm{p}<.05, \mathrm{t}=-8.974)$ in favor of the experimental group.

Table 4. Independent sample t-test results of the critical thinking post-test

\begin{tabular}{cccccc}
\hline Group & $\mathrm{N}$ & Mean & SD & $\mathrm{t}$ & $\mathrm{p}$ \\
\hline Control & 19 & 10.588 & 1.734 & \multirow{2}{*}{8.974} & \multirow{2}{*}{.000} \\
Experimental & 19 & 18.368 & 3.419 & & \\
\hline
\end{tabular}

\section{Results related to the "Analysis" questions of the Critical Thinking test}

In the Critical Thinking test, the analysis skills appear in 7 questions. According to Table 5, results showed that there was no significant difference between the control and experimental groups regarding the "Analysis" questions of the Critical Thinking pre-test $(\mathrm{p}>0.05, \mathrm{t}=.283)$. However, there was a significant difference between the two groups post-test $(\mathrm{p}<0.05, \mathrm{t}=-7.463)$ in favor of the experimental group. This means that the experimental group students" improvement was significantly better than the control group in the "Analysis" questions of the Critical Thinking test.

Table 5. Independent sample t-test results of the "Analysis" questions in the Critical Thinking test

\begin{tabular}{ccccccc}
\hline Test & Group & $\mathrm{N}$ & Mean & SD & $\mathrm{t}$ & $\mathrm{p}$ \\
\hline Pre- test & Control & 19 & 2.315 & 1.056 & \multirow{2}{*}{.283} & .779 \\
& Experimental & 19 & 2.210 & 1.228 & & \\
Post-test & Control & 19 & 2.421 & 1.070 & \multirow{2}{*}{-7.463} & .000 \\
& Experimental & 19 & 5.421 & 1.387 & & \\
\hline
\end{tabular}

\section{Results related to the "Interpretation" questions of the Critical Thinking test}

In the Critical Thinking test, the interpretation skills appear in 7 questions. The t-test results, shown in Table 6, indicated that there was no significant difference between the control and the experimental groups regarding the "Interpretation" questions of the Critical Thinking pre-test $(\mathrm{p}>0.05, \mathrm{t}=.890)$. However, there was a significant difference between both groups post-test $(\mathrm{p}<0.05, \mathrm{t}=-4.454)$ in favor of the experimental group. This means that the experimental group improvement was significantly better than the control group in the "Interpretation" questions of the Critical Thinking test. 
Table 6. Independent sample t-test results of the "Interpretation" questions in the Critical Thinking test

\begin{tabular}{ccccccc}
\hline Test & Group & $\mathrm{N}$ & Mean & SD & $\mathrm{t}$ & $\mathrm{p}$ \\
\hline Pre- test & Control & 19 & 3.526 & 1.389 & .890 & .379 \\
& Experimental & 19 & 3.105 & 1.523 & & \\
Post-test & Control & 19 & 3.473 & 1.123 & & \\
& Experimental & 19 & 5.421 & 1.538 & -4.454 & .000 \\
\hline
\end{tabular}

Results related to the "Argumentation" questions of the Critical Thinking test

In the Critical Thinking test, the argumentation skills appear in 11 questions. The t-test results provided in Table 7, showed that there was no significant difference between the experimental and the control groups regarding the "Argumentation" questions of the Critical Thinking pre-test $(\mathrm{p}>0.05, \mathrm{t}=-1.170)$. However, there was a significant difference between the two groups post-test $(\mathrm{p}<0.05, \mathrm{t}=-5.566)$. This means that the experimental group improvement was significantly better than the control group in the "Argumentation" questions of the Critical Thinking test.

Table 7.Independent sample t-test results of the "Argumentation" questions in the Critical Thinking test

\begin{tabular}{lllllll}
\hline $\begin{array}{l}\text { Critical } \\
\text { thinking test }\end{array}$ & Group & $\mathrm{N}$ & Mean & SD & $\mathrm{t}$ & $\mathrm{p}$ \\
\hline Pre- test & Control & 19 & 3.947 & 1.544 & -1.170 & .250 \\
& Experimental & 19 & 4.526 & 1.504 & & \\
\multirow{3}{*}{ Post-test } & Control & 19 & 4.631 & 1.605 & -5.566 & .000 \\
& Experimental & 19 & 7.473 & 1.540 & \\
\hline
\end{tabular}

\section{Results related to the final exam questions}

Students' results of the "Analysis" question of the final exam

In the final exam given to both groups at the end of the experimental study, the "Analysis" question stated:

\begin{tabular}{|cccc|}
\hline \multicolumn{4}{c|}{ Given the following table, analyze and conclude: } \\
\hline $\begin{array}{c}\text { Content of the test } \\
\text { tube }\end{array}$ & Catalyst & $\begin{array}{l}\text { Beginning } \\
\text { Mass }\end{array}$ & $\begin{array}{c}\text { Final } \\
\text { Mass }\end{array}$ \\
\hline Egg white & Lipase & $5 \mathrm{~g}$ & $5 \mathrm{~g}$ \\
Cream & Lipase & $5 \mathrm{~g}$ & $0 \mathrm{~g}$ \\
Egg white & Protease & $5 \mathrm{~g}$ & $0 \mathrm{~g}$ \\
Cream & Protease & $5 \mathrm{~g}$ & $5 \mathrm{~g}$ \\
\hline
\end{tabular}

The results of the independent-samples t-test regarding the difference between both groups' mean scores on the "Analysis" question of the final exam are provided in the table 8 below. These results show a significant difference $(p<0.05, t=-5.102)$ between the control and the experimental groups in favor of the experimental group.

Table 8. Independent sample t-test results of the final exam "Analysis" question

\begin{tabular}{cccccc}
\hline Group & $\mathrm{N}$ & Mean & SD & $\mathrm{t}$ & $\mathrm{p}$ \\
\hline Control & 19 & 0.735 & 0.903 & \multirow{2}{*}{-5.102} & \multirow{2}{*}{.000} \\
Experimental & 19 & 1.921 & 0.533 & & \\
\hline
\end{tabular}

The "Analysis" question responses were also analyzed qualitatively by grouping the students' responses into categories taking into consideration the level of the analysis skill exhibited in each response. The level ranges from 0 to 5, where 0 represents a null level of analysis and 5 represents the highest level of analysis. Results are displayed in Table 9 showing that most of the experimental group students' responses belonged to the higherlevel categories while most of the control group students' responses belonged to the lower-level categories. Hence the experimental group students improved their "analysis" skill more than the control group students. 
Table 9. Rubric of the responses to the "Analysis" question of the final exam

\begin{tabular}{|c|c|c|c|}
\hline 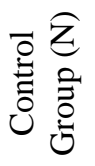 & 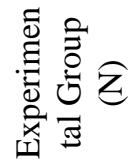 & Answer & d \\
\hline 7 & 0 & - No answer & \\
\hline 2 & 0 & $\begin{array}{l}\text { - Lipase should be used in order to avoid loss of egg white's } \\
\text { mass and the protease should be used in order to avoid loss of } \\
\text { cream's mass. }\end{array}$ & 0 \\
\hline 2 & 0 & - The loss of mass indicates that there is a chemical reaction & \\
\hline 1 & 0 & $\begin{array}{l}\text { - The lipase "has destroyed" cream and the protease "has } \\
\text { destroyed" egg white }\end{array}$ & 1 \\
\hline 1 & 0 & - The lipase is the specific catalyst for cream & \\
\hline 0 & 3 & $\begin{array}{l}\text { - There are chemical reactions in the second and third } \\
\text { experiments, } \\
\text { while there are not in the first and fourth ones }\end{array}$ & \\
\hline 1 & 0 & $\begin{array}{l}\text { - The lipase is the specific catalyst for cream, and the protease } \\
\text { is the specific catalyst for egg white } \\
\text { - The lipase is the specific catalyst for cream, and the protease }\end{array}$ & 2 \\
\hline 0 & 3 & $\begin{array}{l}\text { is the specific catalyst for egg white. There are chemical } \\
\text { reactions in the second and third experiments, while there are } \\
\text { not in the first and fourth ones } \\
\text { - The lipase is the specific catalyst for cream, and the protease }\end{array}$ & 3 \\
\hline 3 & 7 & $\begin{array}{l}\text { is the specific catalyst for egg white that's why there are } \\
\text { chemical reactions in the second and third experiments while } \\
\text { there are not in the first and fourth ones } \\
\text { - The lipase is the specific catalyst for cream, and the protease } \\
\text { is the specific catalyst for egg white that's why there are }\end{array}$ & 4 \\
\hline 2 & 6 & $\begin{array}{l}\text { chemical reactions in the second and third experiments since } \\
\text { the masses of egg white and cream disappeared, while there } \\
\text { are not chemical reactions in the first and fourth experiments } \\
\text { since the masses of egg white and cream didn't change from } \\
\text { the beginning to the end }\end{array}$ & 5 \\
\hline
\end{tabular}

Students' results of the "“Interpretation" question of the final exam

The "Interpretation" question of the final exam stated:

Patient has high stomach acidity. Doctor gives him Tums as medication. Interpret why.

The results of the independent-samples t-test regarding the difference between both groups' scores on the "Interpretation" question of the final exam are provided in the table 10 below. These results show a significant difference ( $\mathrm{p}<0.05, \mathrm{t}=-3.693)$ between the control and the experimental groups in favor of the experimental group.

Table 10. Independent sample t-test results of the final exam "Interpretation" question

\begin{tabular}{cccccc}
\hline Group & $\mathrm{N}$ & Mean & SD & $\mathrm{t}$ & $\mathrm{p}$ \\
\hline Control & 19 & 1.205 & 0.560 & \multirow{2}{*}{-3.693} & \multirow{2}{*}{.001} \\
Experimental & 19 & 1.842 & 0.472 & & \\
\hline
\end{tabular}

The "Interpretation" question responses were also analyzed qualitatively by grouping the students' responses into categories taking into consideration the level of the interpretation skill exhibited in each response. The level ranges from 0 to 5 , where 0 represents a null level of interpretation and 5 represents the highest level of interpretation. Results are displayed in Table 11 showing that most of the experimental group students' responses belonged to the higher-level categories while most of the control group students' responses belonged to the lower-level categories. Hence the experimental group students improved their "interpretation" skill more than the control group students. 
Table 11. Rubric of the responses to the "Interpretation" question of the final exam

\begin{tabular}{|c|c|c|c|}
\hline 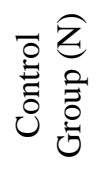 & 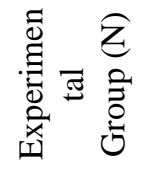 & Answer & 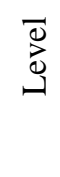 \\
\hline 1 & 0 & No answer & \\
\hline 1 & 0 & Tums "fights" the stomach acidity & 0 \\
\hline 0 & 4 & Tums neutralizes the acidity & \\
\hline 1 & 1 & Tums decreases the amount of acidity & 1 \\
\hline 2 & 0 & Tums is a base & \\
\hline 3 & 0 & Tums is a base which decreases the acidity's amount. & 2 \\
\hline 7 & 0 & $\begin{array}{l}\text { Tums is a base which should be administered } \\
\text { depending on the amount of acidity }\end{array}$ & 3 \\
\hline 4 & 10 & $\begin{array}{l}\text { Tums is a base which decreases the amount of acidity } \\
\text { and neutralizes its excess }\end{array}$ & 4 \\
\hline 0 & 4 & $\begin{array}{l}\text { Tums is a base which decreases the amount of acidity } \\
\text { and neutralizes its excess, according to the following } \\
\text { reaction: } \\
\mathrm{H}^{+}+\mathrm{OH}^{-} \rightarrow \mathrm{H}_{2} \mathrm{O}\end{array}$ & 5 \\
\hline
\end{tabular}

Students' results of the "Argumentation" problem of the final exam

In the final exam, both groups were given an argumentative problem to assess their ability to elaborate arguments, to generate counterarguments and to develop adequate rebuttals to others' counterarguments. The problem included the following questions:

- The hair's shampoo has a $\mathrm{pH}=6$. What do you think; hair's shampoo is an acidic or a basic solution? Justify

- A Chemistry teacher from another school, according to another textbook, told his students: "we can't consider shampoo as an acid, since it doesn't burn skins; therefore, it isn't an acid, it is a base". What counterarguments can you give?

- The chemistry teacher is now talking to you: "the $\mathrm{pH}$ value of 6 could be insufficient for the determination of the shampoo's acidic character; in fact, after our observations in the lab we found that the $\mathrm{pH}$ of the tap water we tested was around 5.5, and we also know that water is neutral, therefore, shampoo could be basic because its $\mathrm{pH}$ is higher than those of the tested water.". Generate rebuttals to the teacher counterargument.

- After considering these two points of view, what do you think: is the shampoo, an acid or a base?

Table 12. Capacity of generating arguments, counterarguments and rebuttals

\begin{tabular}{|c|c|c|c|}
\hline Group & & & Total \\
\hline \multirow{2}{*}{\multicolumn{4}{|c|}{ Arguments }} \\
\hline & Unable & Able & \\
\hline Control & 6 & 12 & 18 \\
\hline Experimental & 0 & 19 & 19 \\
\hline \multicolumn{4}{|c|}{ Counterarguments } \\
\hline & Unable & Able & \\
\hline Control & 18 & 0 & 18 \\
\hline Experimental & 1 & 18 & 19 \\
\hline \multicolumn{4}{|c|}{ Rebuttals } \\
\hline & Unable & Able & \\
\hline Control & 15 & 3 & 18 \\
\hline Experimental & 4 & 15 & 19 \\
\hline
\end{tabular}

According to Table 12, all the experimental group students were able to give adequate arguments, while only 12 out of 18 control group students were able to give adequate ones. In addition, 18 out of 19 students in the experimental group generated adequate counterarguments, while all students in the control group were unable to give adequate ones. Furthermore, 15 students out of 19 in the experimental group were able to generate 
adequate rebuttals, while only three students out of 18 control group students were able to generate adequate ones.

A Chi-Square test was done in order to compare both groups' students' argumentation skills in the final exam. The results of the Chi-Square test regarding the difference between both groups' argumentation skills are provided in the table 13 below. Results showed a significant difference $(\mathrm{p}<0.05)$ between both groups in the capacity of arguing, generating adequate counterarguments and adequate rebuttals to others' counterarguments, according to Table 13 .

Table 13: Chi-Square test results of the "Argumentation" questions in the final exam

\begin{tabular}{cccc}
\hline & $\chi^{2}$ & $\mathrm{df}$ & $\mathrm{p}$ \\
\hline $\begin{array}{c}\text { Capability to generate } \\
\text { arguments }\end{array}$ & 7.559 & 1 & .006 \\
$\begin{array}{c}\text { Capability to generate } \\
\text { counterarguments } \\
\begin{array}{c}\text { Capability to generate } \\
\text { rebuttals }\end{array}\end{array}$ & 33.208 & 1 & .000 \\
\hline
\end{tabular}

Further qualitative analysis revealed that many contradictions and inconsistencies exist in the responses of the control group students, who weren't able neither to maintain their opinion nor to defend it. In fact, in the first question, 17 students had considered the shampoo as an acid, while in the second and third questions, they said that shampoo is a base and an acid at the same time. Only two students didn't agree with the teacher, since they qualified the shampoo as a weak acid so it can't burn the skin. As one student changed his opinion at the end when he considered shampoo as a base (fourth question) since it is a weak acid.

On the other hand, all the experimental group students classified the shampoo as an acid since its $\mathrm{pH}$ is lower than 7, and none of them changed his or her opinion. On the teacher's argument: "if it was an acid, it would burn eyes and skin", eighteen of them gave adequate counterarguments such as: "it is a weak acid" or "it is not a concentrated acid", "its $\mathrm{pH}$ is higher than 1" or "stronger acids such as Pepsi and vinegar don't burn", etc..., the remaining student was unable to generate a counterargument. On the third question, all of the students explained that the $\mathrm{pH}$ of water is lower than 7 because of chemical reactions that took place; in other words, they defended the argument they gave on the first question. Therefore, the majority of the experimental group students elaborated arguments, examined and evaluated opposing side's reasons, and generated rebuttals to other counterarguments presenting a strong and valid argumentative discourse.

\section{Discussion}

Results of this study revealed that the control group students did not produce significant improvement in their critical thinking skills, while, the experimental group students progressed significantly. This was evident from the results of the Critical Thinking test as well as from the final exam. Firstly, the control group students' analysis skills did not improve significantly contrary to the experimental group students who benefited from the I\&R method which accustomed them to analyze their own data and results at the end of each lab session as well as others students' results. Secondly, in the Critical Thinking post-test as well as in the final exam, the control group students' interpretation skills didn't improve significantly in contrary to the experimental group students. The I\&R method positive impact was due to the fact that it trained students to interpret theirs and each other's data and results, and to generalize, conclude and discover the "laws" from the experiment. This result is in line with the Tebabal and Kahssay (2011) findings, whose study has surveyed the effectiveness of student-centered instruction in improving students' graphical interpretation skills. Thirdly, as they were performing argumentation skills during the debates after each lab session, the experimental group students became significantly better than the control group's ones in generating arguments, examining and evaluating opposing side's reasons, generating rebuttals to other counterarguments, and presenting strong and valid argumentative discourses. These results were evident in the final exam as well as in the argumentation questions of the Critical Thinking test. They are in line with the findings of Crowell (2011), and Kuhn et al. (2008), who stressed the importance of providing practice with dialogic argumentation to improve the quality of the dialog itself as well as individual thought, since by engaging in dialogic argumentation, they are exposed to alternative viewpoints and hence gains experience countering them. Moreover, Kuhn (1991) suggested that engaging students in sophisticated argumentative discourse can foster sophisticated thought, with whom Oaksford et al. (2008) agreed, claiming that argumentation is "the more general human process of which more specific forms of reasoning are a part". 
In general, the present work supports earlier findings that inquiry teaching and learning showed positive impact in stimulating students' thinking skills by training students to think divergently at a higher thinking level as well as training the co-development of reasoning strategies and domain knowledge (Echevarria, 2003; Metz, 2004; Schauble, 1996; Tytler \& Peterson, 2004; Zimmerman, 2007). Furthermore, the findings of this study support the findings from previous studies showing the positive effects of metacognitive guidance on learning outcomes (Tien, 1998; Zion, Michalsky, \& Mevarech, 2005).

\section{Implications}

Teachers and curriculum developers could benefit from the study to develop instructional strategies and curricula that help students enhance their critical thinking skills, especially their analysis, interpretation, and argumentation skills. Researchers and educators could plan workshops and seminars for future and in-service teachers. As there is evidence that the I\&R method has improved students' thinking skills, thus, teachers are encouraged to integrate the I\&R teaching method in their classrooms. This could be done easily even in the schools that are not well equipped since the materials and chemical products used in the lab experiments are available and not expensive. In addition, teachers do not need more time to implement the I\&R method since both methods required the same amount of class time.

\section{Limitations and recommendations}

By implementing the I\&R method, we initiate the experimental group students to become critical thinkers as they were trained to make conjectures, to conduct experiments, to study variables, to analyze data, to interpret results, to generate adequate arguments and counterarguments. However, one semester is not enough to generalize the positive impact of the I\&R method likewise its implementation in only one school. This is true for more than one reason. Firstly, some students need more time to adapt themselves with the I\&R method. Secondly, longer instructional periods may be needed for accomplishing the development of young thinkers and researchers. Longitudinal studies may be essential in this respect. Thirdly, this instructional method could be used in other subjects, such as Biology and Physics. Fourthly, it would be better to implement this teaching method in public as well as in private schools in order to compare its impact. Studies in schools in other geographical regions are also needed for a wider generalization, since several variables might influence the results, such as students' socioeconomic backgrounds, teachers' habits and beliefs, and school systems.

\section{Conclusion}

This study was conducted to investigate the impact of the I\&R instructional method on grade 8 students critical thinking. The I\&R method implementation has shown to enhance students' thinking skills, particularly their analysis, interpretation and argumentation skills. By fostering students' critical thinking skills, this instructional teaching method could initiate them to become thinkers and researchers. As critical thinking continues to be an important component in school curricula of the $21^{\text {st }}$ century, we need to find ways to help students improve their abilities to think critically and their disposition to use these skills and strategies that incorporate inquiry and metacognition are shown to be beneficial.

\section{References}

Abdullah, C., Parris, J., Lie, R., Guzdar, A., \& Tour, E. (2015). Critical Analysis of Primary Literature in a Master's- Level Class: Effects on Self-Efficacy and Science-Process Skills. Life Science Education, 14(3), 1-13.

Barroga E, Mitoma H. Critical Thinking and Scientific Writing Skills of Non-Anglophone Medical Students: a Model of Training Course. J Korean Med Sci. 2019 Jan; 34(3):e18.

Bransford, J.D., Brown, A.L., \& Cocking, R.R. (2000). How people learn: brain, mind, experience, and school expanded edition. National Academics Press, Washington DC.

Burke, L.A,. \& Williams, J.M. (2008). Developing young thinkers: An intervention aimed to enhance children's thinking skills. Thinking Skills and Creativity, 3, 104-124.

Caswell, C.J., \& LaBrie, D.J. (2017). Inquiry Based Learning from the Learner's Point of View: A Teacher Candidate's Success Story. Journal of Humanistic Mathematics, 7(2), 160-186. 
Center for Inspired Teaching, Philosophy \& Teaching Approach, web resource, available at http://www.inspiredteaching.org/inspired-teaching-demonstration-school/philosophy, accessed on June 9, 2017.

Changwong, K., Sukkamart, A., \& Sisan, B. (2018). Critical thinking skill development: Analysis of a new learning management model for Thai high schools. Journal of International Studies, 11(2), 37-48.

Crowell, A. (2011). Assessment of a Three -Year Argument Skill Development Curriculum (Doctoral dissertation). Graduate School of Arts and Sciences Columbia University, Colombia.

Duran, M., Dökme, İ.(2016). The effect of the inquiry-based learning approach on student's critical-thinking skills. Eurasia Journal of Mathematics, Science \& Technology Education, 12(12), 2887-2908

Dushl, R., Ellenbogan, K., \& Erduran, S. (1999). Promoting argumentation in middle school science classrooms : A Project SEPIA evaluation. A paper presented at the Annual Meeting of the National Association for Research in Science Teaching, Boston.

Echevarria, M. (2003). Anomalies as a catalyst for middle school students' knowledge construction and scientific reasoning during science inquiry. Journal of Educational Psychology, 95, 357-374.

Fennimore, T.F., \& Tinzmann, M.B. (1990). North central regional education laboratory. NCREL, Oak Brook.

Fisher, R. (2005). Teaching Children to Think. Cheltenham: Stanley Thornes.

Fisher R., Arthur J, Grainger T \& Wray D (2006). Teaching thinking and creativity. Learning to teach in primary school, Routledge Falmer. http://www.routledge.com/books/Learning-to-Teach-in-thePrimary-School- isbn9780415359283.

Kaplan, A. (2017). Evaluation of studies on the critical thinking approach through content analysis. International Journal of New Trends in Arts, Sports \& Science Education, 6(1), 9-17.

Karakoç, M. (2016). The Significance of Critical Thinking Ability in terms of Education. International Journal of Humanities and Social Science, 6(7), 81-84.

Kitot, A.K.A., Ahmad, A.R., \& Seman, A.A. (2010). The effectiveness of inquiry teaching in enhancing students critical thinking. Procedia Social and Behavioral Sciences, 7, 264-273.

Kuhn, D. (1991). The skills of argument. Cambridge, England: Cambridge University Press.

Kuhn, D., Goh, W., lornadou, K., \& Shaenfield, D. (2008). Arguing on the computer: A microgenetic study of developing argument skills in a computer-supported environment. Child Development, 79(5), 13111329.

Livingston, J. (1997). Metacognition: An Overview. Retrieved: http://www.gse.buffalo.edu/fas/shuell/cep564/Metacog.htm.

Magno, C. (2010). The role of metacognitive skills in developing critical thinking. Meatacognition and Learning, 5(2), 137-156.

Metz, K. E. (2004). Children's understanding of scientific inquiry: Their conceptualization of uncertainty in investigations of their own design. Cognition and Instruction, 22, 219-290.

Nussbaun, E., \& Sinatra, G. (2003). Argument and conceptual engagement. Contemporary Educational Psychology,28, 384-395.

Oaksford, M., Chater, N.,\& Hahn, U. (2008). Human reasoning and argumentation: The probabilistic approach. In J. Adler \& L. Rips (Eds.), Reasoning : Studies of human inference and its foundations (pp. 383-413). New York, NY: Cambridge University Press.

Orit Ben-Zevi, A., \& Orion, N. (2005). Development of system thinking skills in the context of earth system education . Journal of Research in Science Teaching, 42(5), 518-560.

O'Rourke, M. (2005). UI critical thinking handbook. University of Idaho.

Padilla, M. J. (1990), Science Process Skills. National Association of Research in Science Teaching Publication: Research Matters - to the Science Teacher (9004). Retrieved from National Association of Research in Science Teaching website: http://www.narst.org/publications/research/skill.cfm

Perry, E. (2016). Every child a scientist: student-centred approaches to active learning in science. In: International Conference on Learning and Teaching: Empowering 21st Century Learners Through Holistic and Enterprising Learning, Kuala Lumpur, Malaysia, 17-18 October 2016. Sheffield Hallam University.

Schneider, W. (2001). Metacognitive development: Educational implications. International Encyclopedia of the Social and Behavioral Sciences. (pp. 9730-9733). Center for Advanced Study in the Behavioral Sciences, Stanford, CA, USA

Smallhorn, M., Young, J., Hunter, N., \& Burke da Silva, K. (2015). Inquiry-based learning to improve student engagement in a large first year topic. Student Success, 6(2), 65-71

Tebabal, A., \& Kahssay, G. (2011). The Effects of Student-Centered Approach in Improving Students' Graphical Interpretation Skills and Conceptual Understanding of Kinematical Motion. Lat. Am. J. Phys. Educ., 5(2), 374-381 
Tytler, R., \& Peterson, T. S. (2004). From "try it and see" to strategic exploration: Characterizing young children's scientific reasoning. Journal of Research in Science Teaching, 41, 94-118.

Uribe Enciso, O.L., Uribe Enciso, D. S., \& Vargas Daza, M. del P. (2017). Critical thinking and its importance in education: some reflections. Rastros Rostros, 19(34). DOI: 10.16925/ra.v19i34.2144

Wang, S. (2017). An exploration into research on critical thinking and its cultivation: an overview. Theory and Practice in Language Studies, 7(12), 1266-1280.

White, B., \& Fredericsen, J. (1998). Inquiry, modeling, and metacognition: Making science accessible to all students. Cognition and Instruction, 16(1), 3-118

White, B., \& Shimoda, T. (1999). Enabling students to construct theories of collaborative inquiry and reflective learning: Computer support for metacognitive development. International Journal of Artificial Intelligence in Education, 10, 151-182

Zagallo, P., Meddleton, S., \& Bolger, M. (2016). Teaching Real Data Interpretation with Models (TRIM): Analysis of Student Dialogue in a Large-Enrollment Cell and Developmental Biology Course. Life Sciences Education, 15(2), 1-18.

Zimmerman, C. (2007). The development of scientific thinking skills in elementary and middle school. Developmental Review, 27, 172-223.

Zion, M., Michalsky, T., \& Mevarech, Z. R. (2005). The effects of metacognitive instruction embedded within an asynchronous learning network on scientific inquiry skills. International Journal of Science Education, 27(8), 957-983.

Zohar, A., Degani, A., \& Vaaknin, E. (2001). Teachers' beliefs about low-achieving students and higher order thinking. Teaching and Teacher Education, 17, 469-485.

Zohar, A., \& Aharon-Kravetsky, S. (2005). Exploring the effects of cognitive conflict and direct teaching for students of different academic levels. Journal of research in science teaching, 42(7), 829-855.

Zulfaneti, Edriati, S., \& Mukhni. (2018). Enhancing Students' Critical Thinking Skills through Critical Thinking Assessment in Calculus Course. Journal of Physics Conference Series 948(1), 20-31.

\begin{tabular}{ll}
\hline \multicolumn{2}{c}{ Author Information } \\
\hline Nathalie Farah & Zalpha Ayoubi \\
Lebanese University, Faculty of Education & Lebanese University, Faculty of Education \\
Contact e-mail: $\underline{\text { nathaly farah@ @otmail.com }}$ & Beirut / Lebanon \\
ORCID iD : 0000-0002-0553-076X & ORCID iD: 0000-0002-9263-5147 \\
\hline
\end{tabular}

